\title{
Observation Impact Study of an Arctic Cyclone Associated with a Tropopause Polar Vortex (TPV)-Induced Rossby Wave Initiation Event
}

\author{
AARON JOHNSON ${ }^{\mathrm{a}}$ AND XUGUANG WANG ${ }^{\mathrm{a}}$ \\ a School of Meteorology, University of Oklahoma, Norman, Oklahoma
}

(Manuscript received 28 August 2020, in final form 23 February 2021)

\begin{abstract}
A case study characterized by Arctic cyclogenesis following a tropopause polar vortex (TPV)-induced Rossby wave initiation event is used to better understand how well existing observations constrain analyses of processes influencing Arctic cyclone predictive skill. Complementary techniques of observation system experiments (OSE) and ensemble sensitivity analysis (ESA) are used to investigate the impacts of existing observation networks on predictions for this case. The ESA reveals that the large-scale Rossby wave structure is correlated with both Arctic cyclone track and amplitude errors. The ensemble analyses of midlevel moisture in the warm conveyor belt region were correlated with forecast cyclone amplitude, but this feature was poorly sampled in existing observations. There is also a sensitivity of Arctic cyclone forecast amplitude error to low-level temperature in the air mass of the cyclogenesis region at analysis time and a sensitivity of Arctic cyclone forecast track error to low-level temperature in the region of an Arctic cold front and a coastal front at the analysis time. The OSEs for this case reveal that Arctic cyclone track error is more sensitive to denial of existing observations than amplitude error. While lower-level (below $700 \mathrm{hPa}$ ) observations had the greatest impact on the surface cyclone during the early stages, upper-level (above $500 \mathrm{hPa}$ ) observations had the dominant impact during its later evolution. Denying temperature from just three well-placed sondes substantially increased track error by degrading analyses of the TPV amplitude and its interaction with the waveguide and developing Rossby wave packet. These results are encouraging for further Arctic cyclone forecast improvements through addition of even a small number of well-placed observations.
\end{abstract}

KEYWORDS: Atmosphere; Arctic; Numerical weather prediction/forecasting; Data assimilation

\section{Introduction}

The importance of Arctic cyclone activity on multiple time scales has gained increasing scientific interest in recent years (Jung et al. 2016). New opportunities for shipping interests are emerging in the Arctic as a result of the decadal-scale decreasing trend in summer sea ice coverage (Smith and Stephenson 2013). The use of Arctic shipping routes would require skillful predictions of Arctic cyclone activity. Arctic cyclones themselves also affect the melting and movement of sea ice on seasonal to subseasonal time scales (e.g., Boisvert et al. 2016), which in turn affects the availability of such shipping routes, among other impacts. Furthermore, there are linkages between Arctic and midlatitude weather, which suggest that improved predictions of Arctic cyclones may provide benefits for midlatitude predictions on weather time scales as well (e.g., Jung et al. 2014; Jung et al. 2015; Kretschmer et al. 2016; Sato et al. 2018; Day et al. 2019). The increasing scientific interest in Arctic cyclone predictability has manifested in large observationfocused field studies such as the Year of Polar Prediction (YOPP; Bradley et al. 2015) and Multidisciplinary drifting Observatory for the Study of Arctic Climate (MOSAiC; IASC 2016).

Many early studies of the key processes leading to the development and maintenance of Arctic cyclones have largely focused on a few "great" Arctic cyclones (e.g., Simmonds and Rudeva 2012; Tanaka et al. 2012; Aizawa et al. 2014; Tao et al.

Corresponding author: Aaron Johnson, ajohns14@ou.edu
2017; Yamagami et al. 2017, 2018). For example, Yamagami et al. (2018) studied the Great Arctic Cyclone of 2012 and found that its track had greater predictability than its amplitude development. Yamagami et al. (2018) found the upperlevel temperature analysis to be particularly important for overall prediction skill. In particular, the cyclone position forecast was most strongly affected by the structure of the large-scale polar vortex while the cyclone amplitude forecast was most strongly affected by the merging of upper-level warm cores [i.e., tropopause polar vortices (TPVs)]. The Great Arctic Cyclone of 2016 was also found to have a track driven by baroclinic processes early in its life cycle, and further development and maintenance of longevity driven by merging with preexisting TPVs (Yamagami et al. 2017).

A common and unique feature of cyclones in the Arctic is that TPVs typically play a key role in their development and maintenance. A TPV is a persistent upper-troposphere potential vorticity (PV) anomaly over polar regions. TPVs typically have a horizontal radius of less than about $1000 \mathrm{~km}$ and a life-span from about a week to as long as a month (Cavallo and Hakim 2009). TPVs owe their longevity to the creation of PV by cloud-top radiative cooling and the radiative impact of the locally enhanced vertical moisture gradient as the tropopause pushes downward within the TPV, as well as the generally reduced large-scale horizontal and vertical wind shears in polar regions (Cavallo and Hakim 2009, 2010, 2013). In addition to the role of TPVs in maintaining a longlasting barotropic structure in the anomalously strong Arctic cyclones described above, TPVs may also indirectly affect Arctic cyclones through the initiation of a Rossby wave 

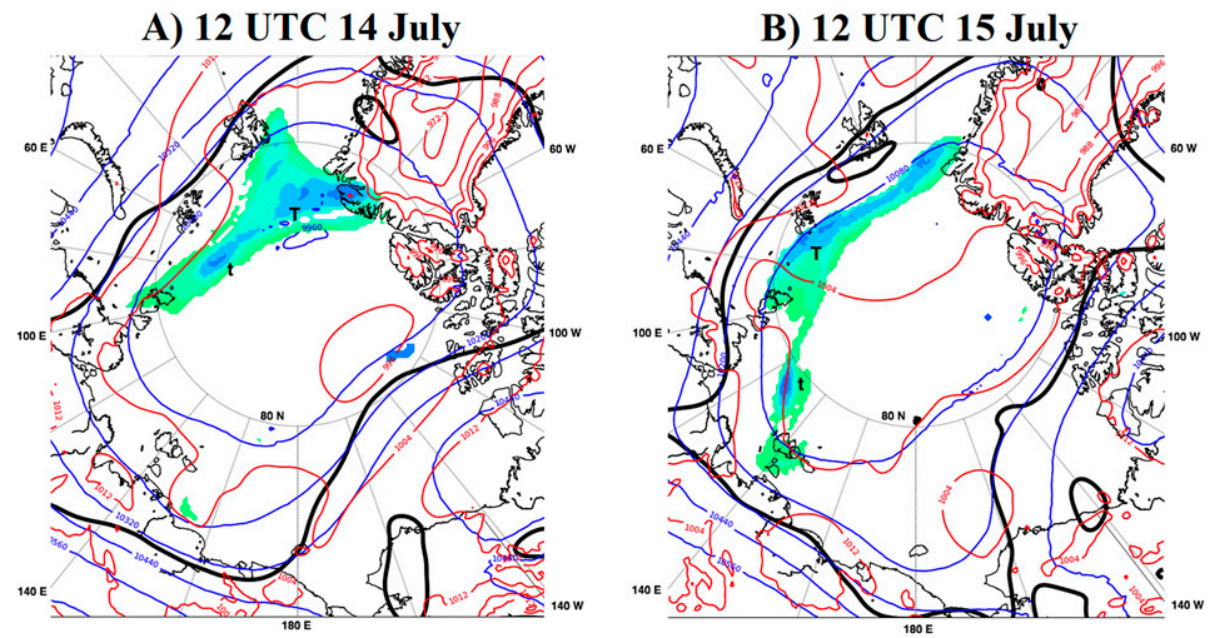

C) 12 UTC 16 July

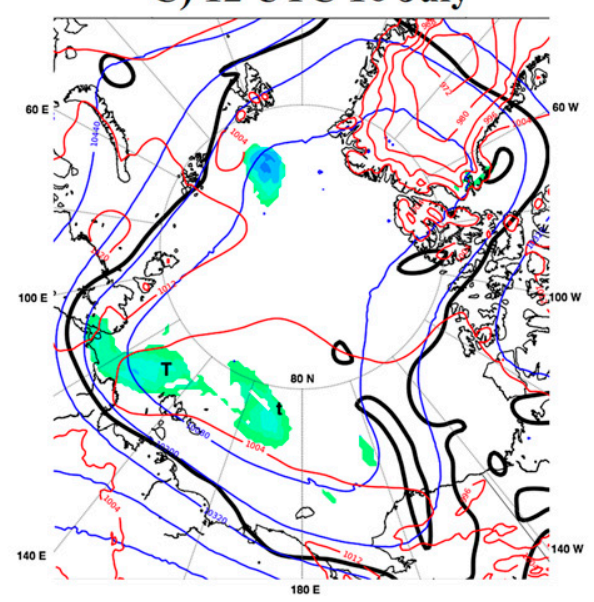

FIG. 1. GFS FNL analyses of temperature on the 2-PVU surface (shading, values below $305 \mathrm{~K}$ plotted only), 250$\mathrm{hPa}$ geopotential height (blue contours), MSLP (red contours), and the 2-PVU contour on the 318-K isentrope (thick black line) at (a) 1200 UTC 14 Jul, (b) 1200 UTC 15 Jul, and (d) 1200 UTC 16 Jul 2018. The letters "T,", "t,", "C," and "c" indicate features discussed in the text.

packet. As noted in Röthlisberger et al. (2018), TPVs are one possible type of jet stream level PV anomaly that can trigger a Rossby wave initiation event if it interacts with a favorable waveguide.

The above studies have illuminated several key processes that are hypothesized to lead to better Arctic cyclone predictions if they are analyzed better during data assimilation (DA). However, there is limited ability to collect in situ observations over the Arctic ocean and satellite data are limited by the poor viewing angle of geostationary satellites, the low contrast between clouds and ice surfaces that can add ambiguity even to polar-orbiting satellites (Taylor et al. 2015), and the limited temporal resolution of polar-orbiting satellites in regions other than the pole itself. Therefore, there remains a need for practical guidance on how to improve the currently sparse network of Arctic observations in order to achieve these benefits. Some initial studies have shown that the inclusion of high temporal frequency ship-based sonde observations in the Arctic ocean during DA can lead to improved Arctic cyclone predictions (Inoue et al. 2013; Yamazaki et al. 2015). It remains unclear which processes related to Arctic cyclogenesis are properly sampled by existing operational observation networks, thus contributing to Arctic cyclone forecast skill.

In this paper, we describe a case study of an Arctic cyclone of relatively modest intensity and longevity. This case is selected because it includes multiple processes hypothesized to be necessary to observe well in order to maximize Arctic cyclone prediction skill. These processes include a long-lived TPV that participated both in the initiation of the large-scale Rossby wave packet that first induces baroclinic cyclogenesis and in the transition to barotropic structure that maintains the longevity of the mature cyclone. The event is described in more detail in section 2, along with the details of the experiment design. Results are then presented in section 3 while section 4 contains a summary and discussion of conclusions. 
A) 06 UTC 17 July

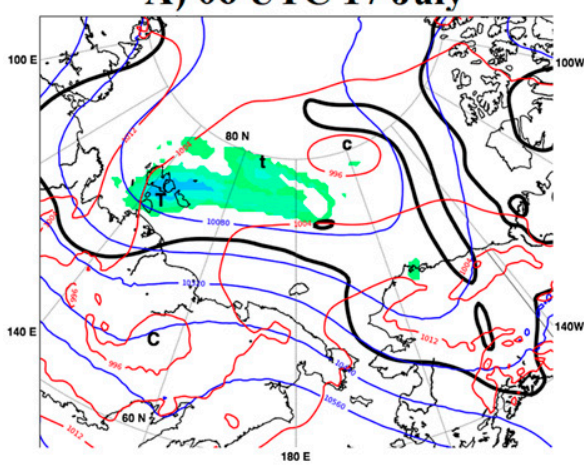

C) 06 UTC 19 July

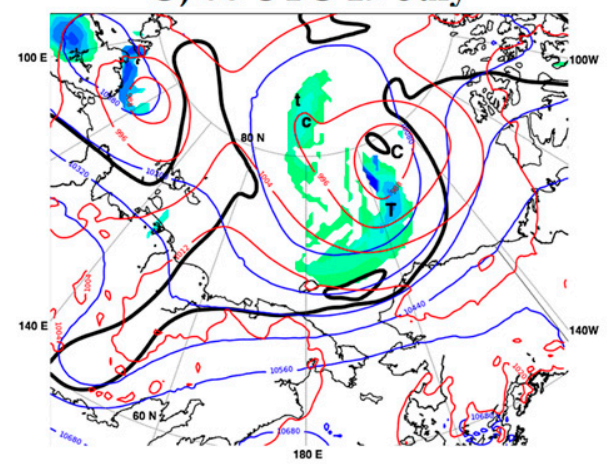

B) 06 UTC 18 July

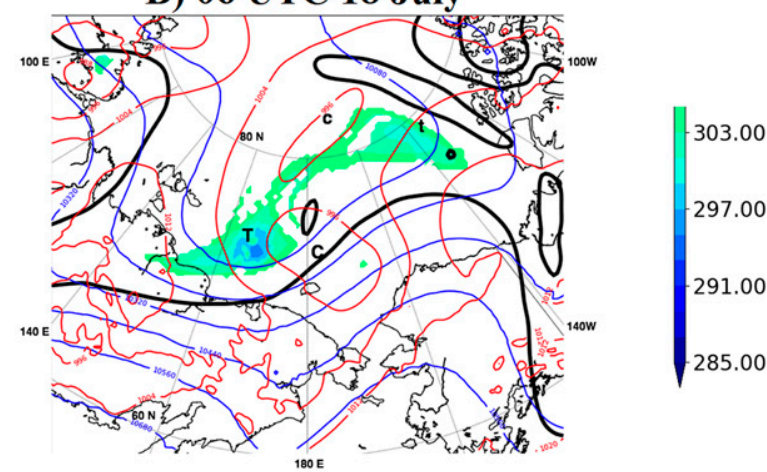

D) 06 UTC 20 July

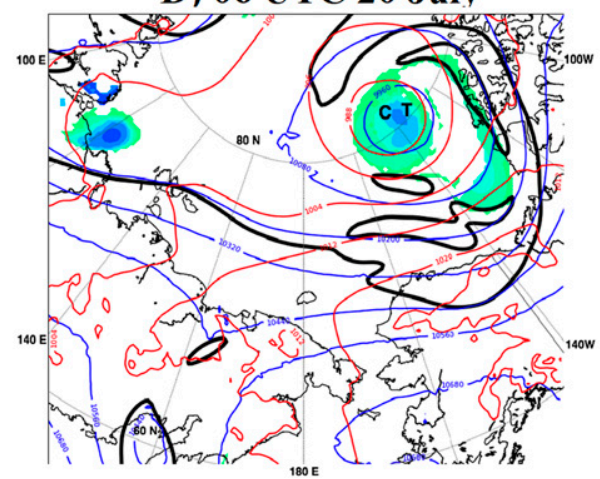

FIG. 2. As in Fig. 1, but for (a) 0600 UTC 17 Jul, (b) 0600 UTC 18 Jul, (c) 0600 UTC 19 Jul, and (d) 0600 UTC 20 Jul 2018.

\section{Methods}

The unique aspect of this case study is that the TPV plays a role in the Rossby wave initiation (RWI) that leads to the downstream Arctic cyclogenesis and then the TPV also plays a role in further strengthening and maintaining the Arctic cyclone as the TPV merges with the Arctic cyclone. The evolution of the Arctic cyclone in the context of these processes is described first in section 2a below. This context is important for interpreting the results of subsequent observation assimilation experiments because the observation impacts are related to the physical processes sampled by such observations. The data assimilation system configuration is then described in sections $2 \mathrm{~b}$ and $2 \mathrm{c}$.

\section{a. Case study overview}

The initial surface cyclogenesis of this event occurs in response to a RWI event induced by a preexisting TPV (Fig. 1). A RWI occurs when a zonal, unperturbed jet stream (i.e., a waveguide; Wirth et al. 2018) begins to undulate in response to some finite perturbation unrelated to development of an upstream wave (Röthlisberger et al. 2018). The amplification of the Arctic jet stream summarized in Fig. 1, including 250-hPa height contours, which are near the level of maximum wind in the jet stream, satisfies the objective RWI criteria from Röthlisberger et al. (2018). In short, a long-lived TPV (labeled "T" in Fig. 1) that can be traced back to an Arctic cyclogenesis event on 8 July (not shown) perturbed the waveguide [2-PVU contour (1 PVU $=10^{-6} \mathrm{~K} \mathrm{~kg}^{-1} \mathrm{~m}^{2} \mathrm{~s}^{-1}$ ) along $318-\mathrm{K}$ isentrope in Fig. 1] that was previously approximately zonal, leading to the amplification and downstream propagation of a Rossby wave packet. By 0600 UTC 17 July there was a weak surface trough associated with TPV T, as well as a more pronounced MSLP minimum (" $\mathrm{C}$ " in Fig. 2) in northern Siberia downstream of the large-scale trough. Although the surface cyclone maintained its MSLP as it moved into the Chukchi Sea (Fig. 2b), at 0600 UTC 19 July (Fig. 2c), further amplification of surface cyclone $\mathrm{C}$ occurred as TPV T approached surface cyclone C. Later in the event, the TPV was stacked atop the persisting surface cyclone for several days (Fig. 2d), consistent with the barotropic structure that has been shown to contribute to the maintenance of other Arctic cyclones (e.g., Yamagami et al. 2017).

In addition to the primary features described above, there are some secondary features that also contribute to the evolution of the Arctic cyclone. Separate from the primary TPV (T), there is a weaker TPV (labeled "t") that splits off from TPV T (Fig. 1a) and induces a weaker surface cyclone (labeled "c") over the Arctic ocean (e.g., Fig. 2a) preceding the baroclinic cyclogenesis of interest. The circulation around this weaker antecedent cyclone is important because it helps form a low-level cold front at the leading edge of the air mass originating over the thick polar sea ice. This cold front (Figs. 2a,b) 
appears to play a role in guiding the track of the Arctic cyclone that subsequently develops, as discussed further in section 3 .

\section{b. Data assimilation and forecast system configuration}

The DA experiments in this study use the Gridpoint Statistical Interpolation (GSI)-based EnKF (Whitaker and Hamill 2002; Wang et al. 2013; Wang and Lei 2014) coupled with version 4.1 of the Advanced Research version of the Weather Research and Forecasting (WRF) Model (ARW; Skamarock et al. 2008) with Polar modifications (PWRF; Hines and Bromwich 2008, 2017; Hines et al. 2011; Wilson et al. 2011, 2012) to assimilate conventional surface and upper-air observations from the operational GTS data stream. As seen in a representative example of the coverage of the National Centers for Environmental Prediction (NCEP) current operational observation networks (Fig. 3), there is a relative lack of observations over the Arctic ocean compared to lower-latitude regions. It is therefore particularly important to better understand the impacts of the observations that are available and where additional observations may potentially provide further benefits.

The initial ensemble comprises 20 members each from analyses in the 0000 UTC 16 July 2018 NCEP Global Ensemble Forecast System (GEFS; Zhou et al. 2017) cycle and 6-h forecasts from the 1800 UTC 15 July 2018 GEFS cycle. The 40-member ensemble is advanced forward in time using the PWRF version 4.1. Physics configurations include the Noah land surface model (Barlage et al. 2010) as modified for polar regions (Hines and Bromwich 2008; Hines et al. 2015; Bromwich et al. 2009), two moment Morrison (Morrison et al. 2005, 2009) microphysics with modified cloud condensation nuclei concentration for polar regions (Hines and Bromwich 2017), rapid radiative transfer model (RRTMG; Clough et al. 2005), and Yonsei University (YSU; Noh et al. 2003) boundary layer. Only the YSU boundary layer deviates from the PWRF configuration used in past studies such as Hines and Bromwich (2017). This change is made based on preliminary sensitivity tests in which we found a reduced low-level temperature bias in the region of interest when switching to the YSU scheme (not shown).

The DA update is performed every $3 \mathrm{~h}$ from 0300 UTC 16 July to 0000 UTC 17 July. Horizontal and vertical localization is applied using the Gaspari and Cohn (1999) function with a cutoff distance of $1000 \mathrm{~km}$ and 1.1 scale height units, respectively, and Relaxation To Prior Spread posterior inflation with a factor of 0.95 (Whitaker and Hamill 2012). For moisture observations only, the vertical localization is reduced to 0.35 scale height units. This scale height is selected to be consistent with the frequent presence of vertically thin layers with strong moisture gradients seen in this case. Furthermore, sensitivity experiments to optimize the performance of free forecasts initialized from the ensemble mean analysis at 0000 UTC 17 July also guided this choice. Moisture observations are only assimilated up to an altitude of $300 \mathrm{hPa}$.

\section{c. Experiment design}

The experiments evaluated in this study are summarized in Table 1 and the DA configuration is summarized in Fig. 4. The baseline experiment forecast is initialized from the ensemble

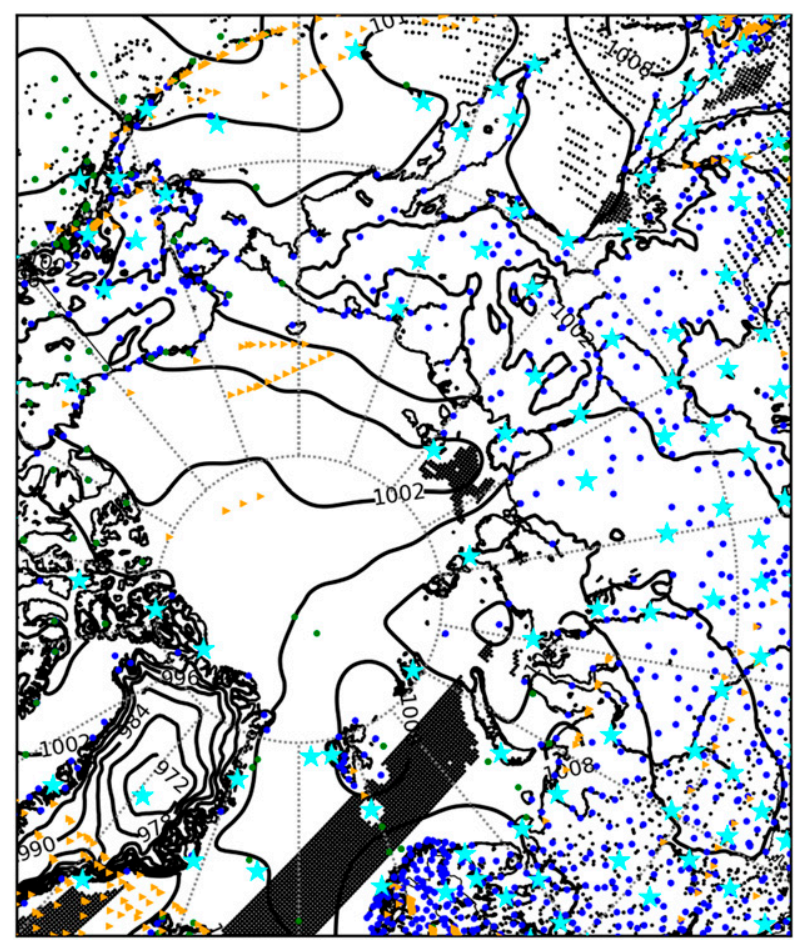

FIG. 3. Representative distribution of observations at 1200 UTC $16 \mathrm{Jul}$. Black dots indicate satellite retrievals, blue dots are surface or buoy data, cyan stars are sondes, and orange triangles are aircraft observations.

mean analysis at 0000 UTC 17 July and run to 1200 UTC 21 July. The 0000 UTC 17 July analysis is the product of $24 \mathrm{~h}$ of cycled DA with a 3-h cycling interval (Fig. 4). A deterministic forecast (noda) is also initialized from the initial ensemble mean at 0000 UTC 16 July in order to quantify the impact of the DA on forecast performance compared to a forecast that did not benefit from the 24-h DA period. A series of data denial, or Observation System Experiments (OSEs) are then conducted. The experiments denyupper and denylower omit observations above $500 \mathrm{hPa}$ and below $700 \mathrm{hPa}$, respectively, in order to quantify the relative impact of the existing upper- and lower-troposphere observations on forecasts of the Arctic cyclone track and amplitude. The 500-hPa level is below the tropopause in the region of the TPV during the DA period

TABLE 1. Summary of forecast experiments resulting from omitting different subsets of observations from the data assimilation.

\begin{tabular}{ll}
\hline \hline Expt name & \multicolumn{1}{c}{ Observations denied during DA } \\
\hline Baseline & None \\
boda & All \\
denyupper & All above $500 \mathrm{hPa}$ \\
denylower & All below $700 \mathrm{hPa}$ \\
ose3 & All variables from three well-placed sondes \\
ose3_t & Temperature from three well-placed sondes \\
ose3_q & Moisture from three well-placed sondes \\
ose3_uv & Wind from three well-placed sondes \\
\hline
\end{tabular}




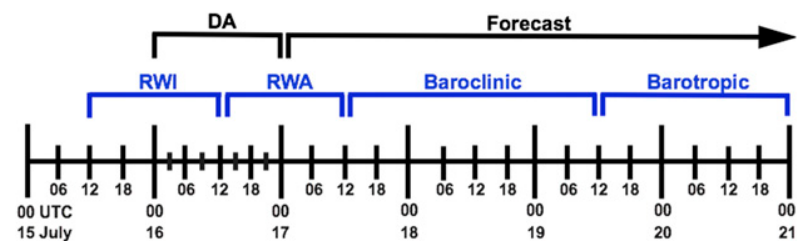

RWI = Rossby Wave Initiation

RWA = Rossby Wave Amplification

DA = Data Assimilation

FIG. 4. Diagram of DA cycle and forecast periods, also showing time periods of key phases of the Arctic cyclone discussed in the text.

while the $700-\mathrm{hPa}$ level is above the low-level Arctic air mass, even over land regions. An experiment referred to as ose 3 consists of omitting the sonde observations from three stations selected for their proximity to the region of cyclogenesis (circled in Fig. 5) in order to quantify the impact on forecast performance of just three particularly well-placed sondes for this event. The impact of removing a small number of observations from the baseline experiment can conversely be interpreted as the impact of adding a small number of observations to the data denial experiment. Therefore, given the generally sparse coverage of Arctic sonde observations, this experiment can provide reasonable guidance on the further benefit that may result from adding even a small number of observations to the existing operational observational network. Such an inference would require the added observation to be well-placed in currently unobserved regions with similar forecast sensitivity as the case examined herein. Finally, experiments ose $3 \_t$, ose $3 \_q$, and $o s e 3 \_u v$ are similar to ose 3 , except that only temperature, moisture, and wind, respectively, is omitted from the three selected sonde stations. This experiment investigates the relative importance of nearby sonde observations of specific thermodynamic and kinematic variables for predicting details of the RWI-induced Arctic cyclogenesis event. The OSE experiments are also evaluated using deterministic forecasts initialized from the ensemble mean analysis at 0000 UTC 17 July.

In addition to the deterministic forecasts that are used to evaluate the impact of existing observations, a 40-member ensemble forecast is also initialized from the 0000 UTC 17 July analysis ensemble in the baseline experiment. These ensemble member forecasts are used for an ensemble sensitivity analysis (ESA; Ancell and Hakim 2007; Torn and Hakim 2008; Kerr et al. 2019) to identify which processes correlate to the forecast error metrics. The ESA is used in this study to identify features that are dynamically linked to the forecast error metrics (e.g., Bednarczyk and Ancell 2015), and thus provides context by which the OSE results can be better understood. Forecast errors are quantified in terms of amplitude (minimum MSLP) errors and location (great circle distance), or track, errors of the forecast cyclones. The ESA was also evaluated separately for latitude error and track error, but the results were generally consistent with the total track error.

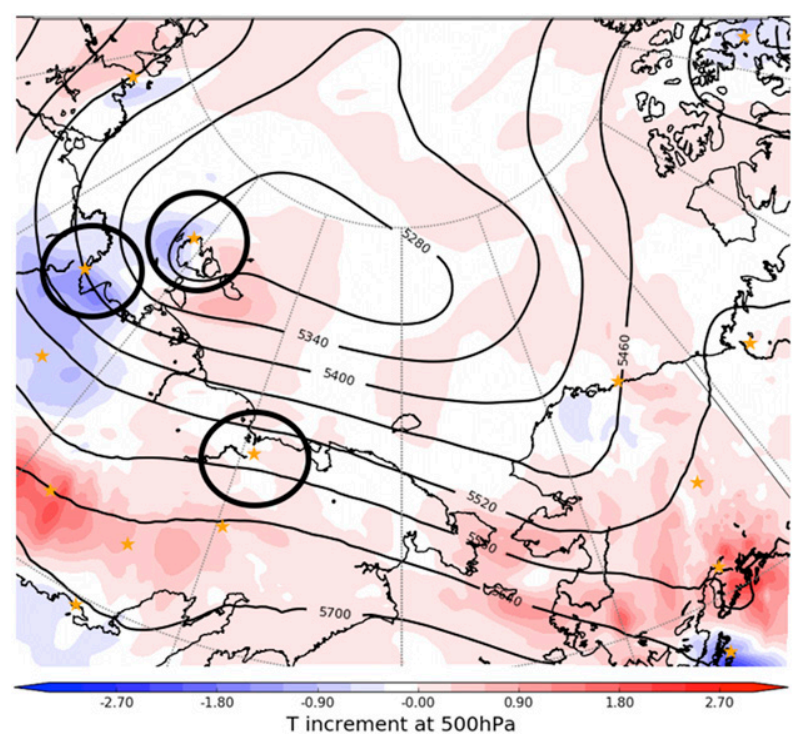

FIG. 5. Temperature increment at $500 \mathrm{hPa}$ during the final cycle of the baseline DA experiment, with sonde locations overlaid as orange stars. The three sondes selected for the ose 3 experiments are highlighted with black circles.

\section{Results}

\section{a. Impact of data assimilation}

At 0600 UTC 18 July (30-h lead time; Fig. 6a), the baseline forecast shows a surface cyclone (red contour) developing in about the correct location and a little deeper than shown in the GFS analysis (black contour). By 0600 UTC 19 July (54-h lead time; Fig. 6b), the baseline forecast has a surface cyclone (red contour) with about the correct amplitude, but a little farther southeast than the observed cyclone as represented in the GFS analysis (black contour). While the GFS analysis has a single broad primary pressure minimum at this time (Fig. 6b, black contour), the baseline forecast still has a somewhat double minimum structure (Fig. 6b, red contour) as the primary surface cyclone has not overtaken the antecedent surface cyclone as completely as in the GFS analysis. At 0600 UTC 20 July (78$\mathrm{h}$ lead time; Fig. 6c), the baseline forecast surface cyclone (red contour) is displaced a little northeastward relative to the GFS analysis surface cyclone (black contour). In terms of the TPV, at 0600 UTC 18 July (Fig. 6a) the baseline forecast TPV (orange contour) is displaced a little northwestward relative to the GFS analysis TPV (gray contour). By 0600 UTC 19 July (Fig. 6b), the analysis TPV (gray contour) has caught up to the surface cyclone (black contour), while the baseline forecast TPV (orange contour) stretches from northeast Siberia to just upstream of the surface cyclone (red contour). At 0600 UTC 20 July (Fig. 6c), the GFS analysis (gray and black contours) and baseline forecast (orange and red contours) both have a TPV stacked atop the surface cyclone. In general, the evolution of the Arctic cyclone is predicted well in the baseline forecast, including both the track and amplitude of the surface pressure minimum, although there is likely still room for additional improvement in the forecast, especially in terms of the TPV evolution. 

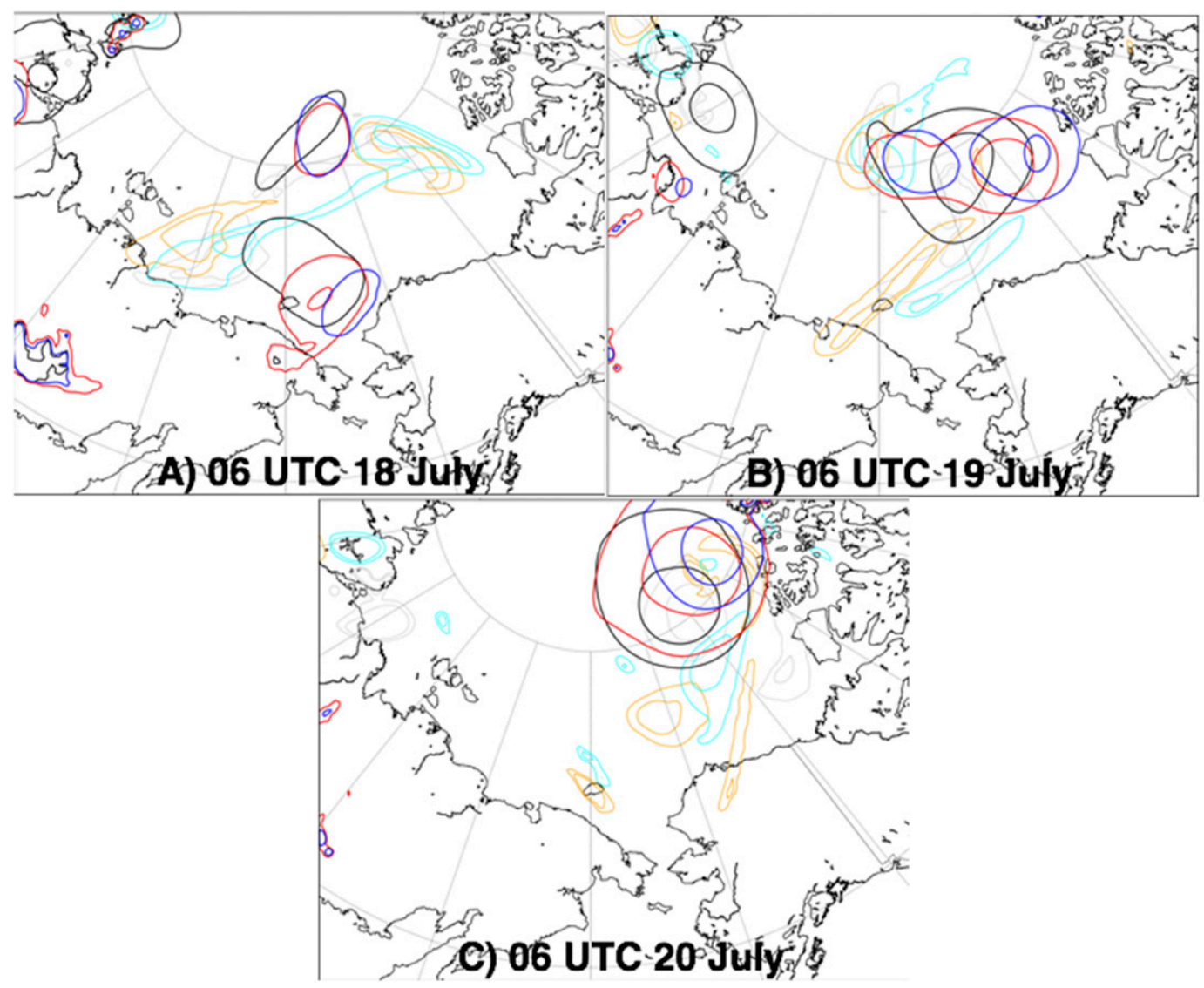

FIG. 6. Key surface and tropopause level features at (a) 0600 UTC 18 Jul, (b) 0600 UTC 19 Jul, and (c) 0600 UTC $20 \mathrm{Jul}$. Black, red, and blue contours are surface pressure in GFS analysis, baseline forecast, and noda forecast, respectively, at the 988- and 994-hPa contour levels. Gray, orange, and cyan contours are potential temperature on the 2-PVU surface in GFS analysis, baseline forecast, and noda forecast, respectively, at the 301- and 304-K contour levels.

In contrast to the baseline forecast, the noda forecast shows a cyclone that is weaker and farther east. For example, at 0600 UTC 18 July (Fig. 6a) the noda forecast shows a weaker and eastward-displaced cyclone (blue contour), compared to the baseline forecast (red contour). While the primary TPV in the noda forecast (cyan contour) matches the location of the GFS analysis TPV (gray contour) at this time, the TPV is not as disconnected from the antecedent TPV in the noda forecast as the GFS analysis. The noda forecast surface cyclone (red contour) and TPV (orange contour) both then develop along a track that is farther east than the baseline forecast (blue and cyan contour, respectively; Fig. 6b). By 0600 UTC 20 July (Fig. 6c), the noda forecast cyclone is even farther east, and dissipating faster than, the baseline forecast cyclone. There is only a small TPV contour (cyan contour) at the center of the noda surface cyclone (blue contour) at this time, while most of the TPV remains upstream of the noda surface cyclone (Fig. 6c). Thus, the assimilated observations are contributing substantially to the accuracy of the baseline forecast by weakening the antecedent cyclone, strengthening and maintaining the intensity of the cyclone of interest, and correcting the cyclone track toward the west. The above qualitative differences are reflected quantitatively in the reductions of forecast error in baseline, compared to noda, for both the track and amplitude of the cyclone (Fig. 7). The baseline Arctic cyclone track error in particular has a confidence interval, based on two standard deviations of track error in individual ensemble member forecasts, that does not overlap with the noda Arctic cyclone track error at most times (Fig. 7a). The ensemble-based two standard deviation (i.e., 95\%) confidence interval reflects the uncertainty of using a single forecast on this case, rather than the uncertainty of how representative the case is of other scenarios. The observation system experiments described below show the specific impacts of different subsets of the assimilated observations on the forecast performance.

\section{b. Ensemble sensitivity analysis (ESA)}

The ESA (Ancell and Hakim 2007; Torn and Hakim 2008; Bednarczyk and Ancell 2015; Kerr et al. 2019) was conducted using both location and amplitude errors of the predicted Arctic cyclone, as quantified by the minimum sea level pressure at the 48-h forecast lead time (0000 UTC 19 July). The equation used to calculate the ensemble sensitivity exactly follows Torn and Hakim [2008, their Eq. (1)]. In short, the 

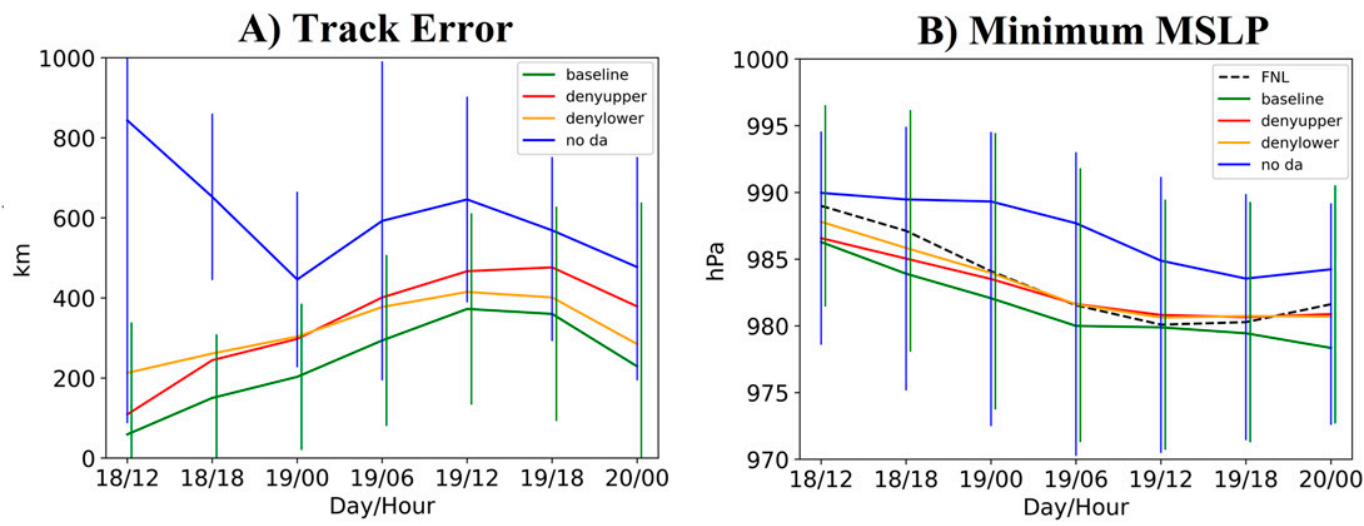

FIG. 7. Forecast (a) Arctic cyclone track error and (b) minimum surface pressure for the noda, baseline, denyupper, and denylower experiments. Confidence intervals of the noda and baseline deterministic forecast error show plus and minus two standard deviations of the errors from individual ensemble members.

ensemble sensitivity is interpreted as the change in the response variable corresponding to a change in the sensitive variable. For example, an ensemble sensitivity value of $1 \mathrm{hPa} \mathrm{K}^{-1}$ indicates that within the ensemble forecast, a $1-\mathrm{K}$ change in temperature at the sensitive time corresponds to a 1-hPa-higher value of the response variable (i.e., minimum sea level pressure). The 40-member ensemble used for the ESA was initialized from the ensemble analyses in the baseline experiment described above. The spread of the response variables, as well as the observed value from the corresponding GFS analysis, are shown in Fig. 8. Results are primarily presented in terms of the 48 -h ensemble forecast sensitivity to perturbations at analysis time, although the 48-h forecast sensitivity to shorter lead time forecasts between 0 and $48 \mathrm{~h}$ were also examined for temporal continuity of the statistically significant features following Chang et al. (2013). Statistical significance of the ESA is indicated where the $\mathrm{p}$ value of the correlation coefficient between the sensitive variable and response variable is less than 0.1 (i.e., $90 \%$ confidence level).

The ensemble sensitivity to initial temperature at the 2-PVU tropopause level for the cyclone amplitude (Fig. 9a) and track error (Fig. 9b) reveal a large-scale dipole structure related to the position of the jet stream and Rossby wave phase corresponding to the generally positive values upstream of the primary TPV and trough axis and negative values downstream of the TPV and trough axis. In particular, the amplitude error corresponds to a northwest-southeast Rossby wave phase shift whereby a more progressive Rossby wave pattern has higher minimum MSLP (i.e., a weaker cyclone). The track errors correspond to a more west-east displacement in the location of the large-scale Rossby wave. In contrast to the amplitude sensitivity (Fig. 9a), the track sensitivity (Fig. 9b) indicates sensitivity in the region of the leading, weaker TPV (black circle in Fig. 9b). This difference between amplitude and track sensitivity is consistent with the interpretation that the strength of the leading TPV affects the strength of the antecedent lowlevel circulation, which affects the location of the cold front that the Arctic cyclone tracks along (Fig. 2). Sensitive regions for temperature at $500 \mathrm{hPa}$ and moisture at $2 \mathrm{PVU}$ were small in scale and did not exhibit temporal continuity from the analysis time sensitivity to the sensitivity at other forecast lead times, and are therefore not shown.

The 500-hPa moisture ESA reveals a coherent area of significant sensitivity for amplitude (Fig. 10a) immediately downstream of the midlevel shortwave trough associated with the TPV of interest. This feature is coherent in time, amplifying during the forecast period (Fig. 10c). This amplification and coherence contrast with the elongated dipole of moisture sensitivity of the track error, related to the north-south positioning of a midlevel moisture plume (Fig. 10b), which does not persist coherently throughout the forecast period (Fig. 10d). The amplitude sensitivity to midlevel moisture in Fig. 10a is

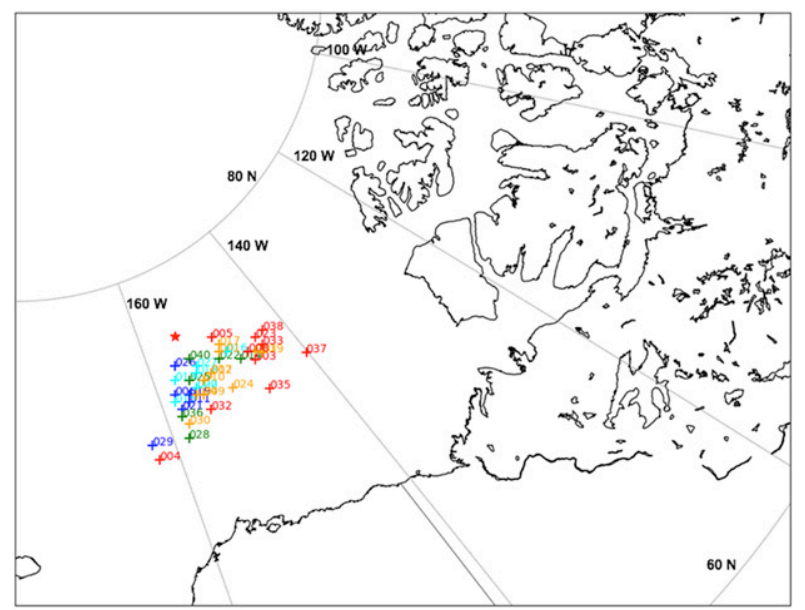

FIG. 8. Location of MSLP minima from each ensemble member forecast valid at the 48-h lead time of 0000 UTC 19 Jul (plus signs markers) and location of the GFS analysis MSLP minimum at the same time (stars). The color of the markers indicates the cyclone amplitude: red, MSLP $>985 \mathrm{hPa}$; orange, $982<\mathrm{MSLP} \leq 985 \mathrm{hPa}$; green, $979<$ MSLP $\leq 982 \mathrm{hPa}$; cyan, $976<\mathrm{MSLP} \leq 979 \mathrm{hPa}$; and blue, $\mathrm{MSLP} \leq 976 \mathrm{hPa}$. 

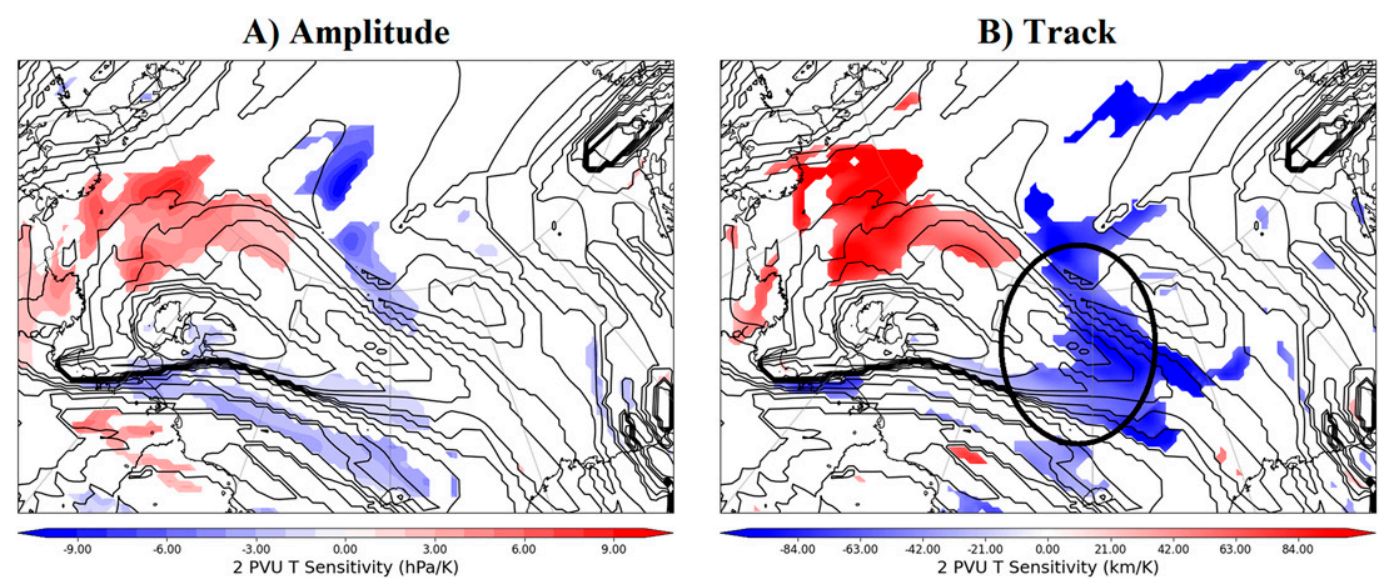

FIG. 9. Ensemble sensitivity of Arctic cyclone (a) amplitude and (b) track error to initial-time potential temperature on the 2-PVU surface (shading). Only values statistically significant at the $90 \%$ level are plotted. Initial time ensemble mean potential temperature on the 2-PVU surface is also shown (black contours) and the black circle in (b) highlights the feature discussed in the text.

particularly interesting because it corresponds to the region where the warm conveyor belt (WCB) is known to transport moisture both meridionally and vertically (e.g., Sodemann and Stohl 2013). While most of the moisture transport in WCBs occurs at levels below $500 \mathrm{hPa}$, this result suggests the vertical extent of the transported moisture correlates most clearly to the forecast amplitude error in this case.

Both amplitude and track sensitivities to $500-\mathrm{hPa}$ geopotential height (i.e., temperature integrated through a deeper layer; Fig. 11b) suggest potential importance of the downstream ridge amplitude and the secondary TPV shortwave (Figs. 11a,b) for the predictability of this Arctic cyclone. In short, a flatter, more progressive, ridge and stronger secondary TPV both correspond to increased track error and higher minimum MSLP (i.e., a weaker cyclone). However, only the track error is clearly sensitive to the amplitude of the midlevel disturbance beneath the primary TPV (Fig. 11b), in that higher heights in the midlevel disturbance (i.e., it has less amplitude) correspond to greater track error. This connects to the other ESA results, which highlighted the large-scale phase differences in the Rossby wave, in that a weaker disturbance perturbs the waveguide less during DA, resulting in a less amplified and more progressive Rossby wave packet during cyclogenesis.

In addition to the upper-level features, the ESA also reveals some potentially important low-level features. In particular, the amplitude sensitivity to temperature at $850 \mathrm{hPa}$ shows a broad, but sporadic, sensitivity of the same sign in the air mass over Siberia where the cyclogenesis begins (Fig. 12a). The corresponding track sensitivity (Fig. 12b) highlights both the location of the Arctic ocean cold front discussed previously, and the coastal baroclinic region along the boundary between the Siberian and Arctic ocean air masses. Low-level moisture sensitivity did not reveal a clear signal (not shown), possibly because low-level moisture errors are more sensitive to physics errors that are shared by all ensemble members and beyond the scope of this study.

\section{c. Observation system experiments (OSEs)}

The ESA results in section $3 b$ highlight some of the physical features and processes that correspond to Arctic cyclone track and forecast errors at the 48-h lead time. These features provide context for understanding the impacts of available sonde observations in the OSE results in this subsection. The first OSE compares the contribution from the existing operational observations at upper levels versus lower levels, starting at 1200 UTC 18 July since this is when a clearly defined surface cyclone can be distinguished in all forecasts. Since there are no splits or merges of surface cyclones in the region during the verification period, the surface cyclone center is tracked using a simple search in the region for the minimum MSLP. Figure 7 shows that the baseline forecast has track error of the surface cyclone center that is several hundred kilometers less than the noda forecast (Fig. 7a), while the amplitude is over forecast by a couple $\mathrm{hPa}$ rather than under forecast by about $5 \mathrm{hPa}$ in noda (Fig. 7b), although the difference is not outside the two standard deviation confidence interval of baseline. The experiment denying lowerlevel observations from the data assimilation (orange line in Fig. 7) has the greatest impact on track error during the earlier forecast lead times while denying the upper-level observations (red line in Fig. 7) has the greatest impact on track error at the later forecast lead times (Fig. 7a). This is consistent with expectations since the lower-level observations can more directly constrain the (low-level) surface cyclone being verified against, while the upper-level observations may take more time to propagate information down to the surface cyclone. The cyclone amplitude is actually closer to the observed amplitude in the denyupper and denylower experiments (Fig. 7b), although all experiments except for noda are within a couple of hPa of the observed amplitude. Thus, the differences in amplitude between denyupper, denylower, and baseline are considered negligible, suggesting that the track error is more clearly sensitive than amplitude error to the 
A) 00 UTC 19 July Amplitude sensitivity at 00 UTC 17 July

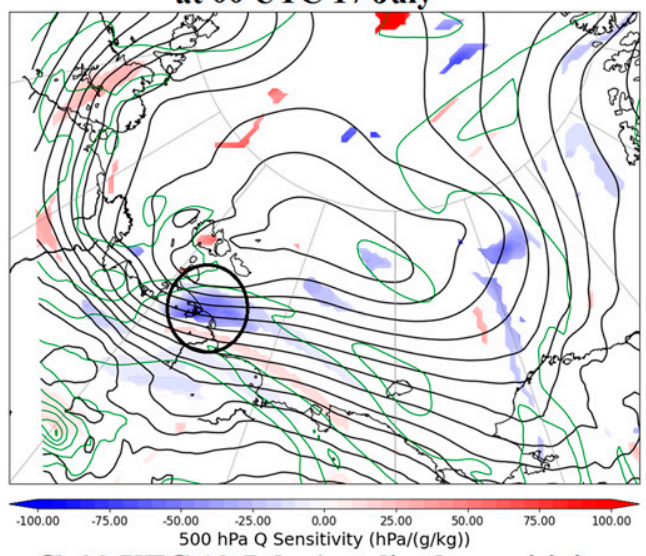

C) 00 UTC 19 July Amplitude sensitivity at 12 UTC 17 July

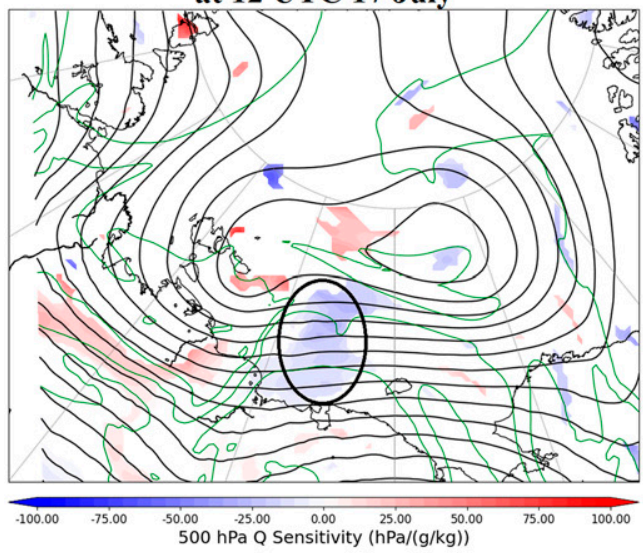

E) 00 UTC 19 July Amplitude sensitivity at 00 UTC 18 July

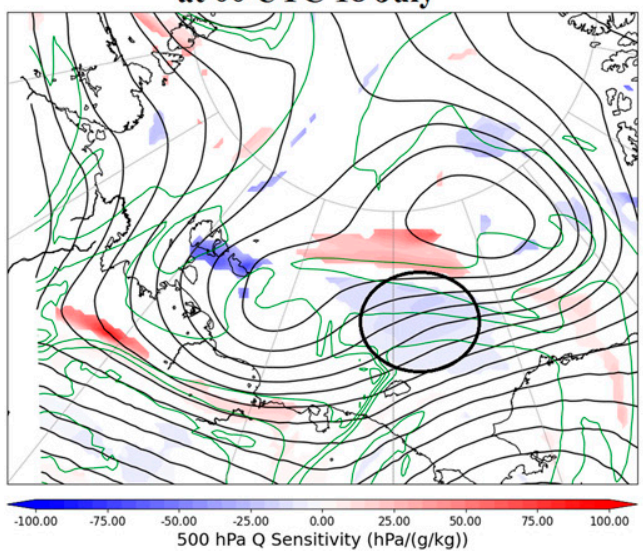

B) 00 UTC 19 July Track Error sensitivity at 00 UTC 17 July

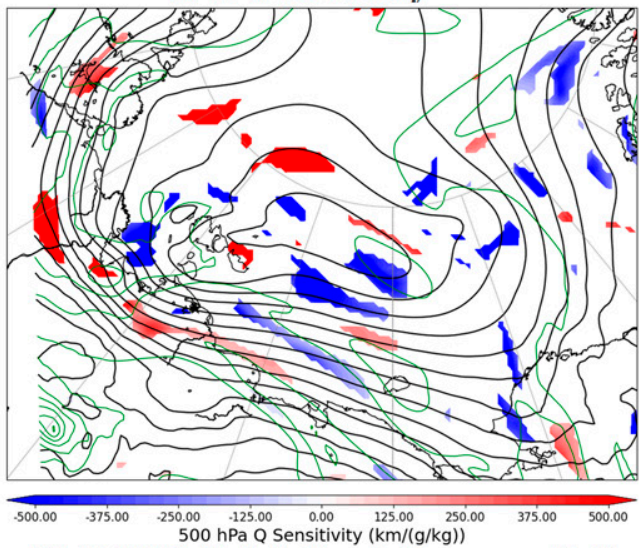

D) 00 UTC 19 July Track Error sensitivity at 12 UTC 17 July

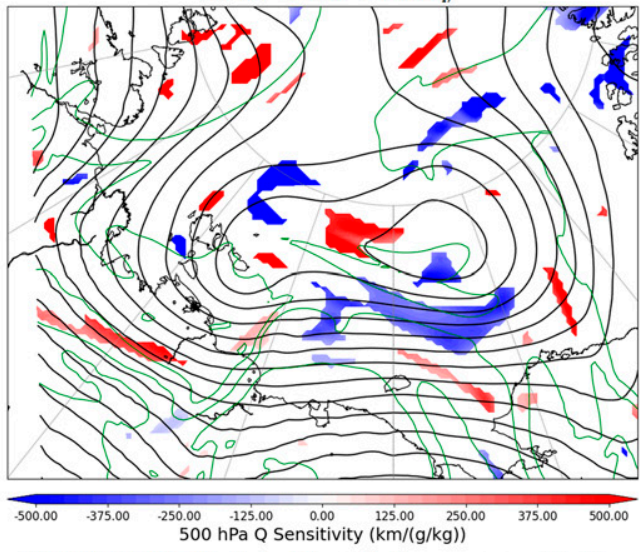

F) 00 UTC 19 July Track Error sensitivity at 00 UTC 18 July

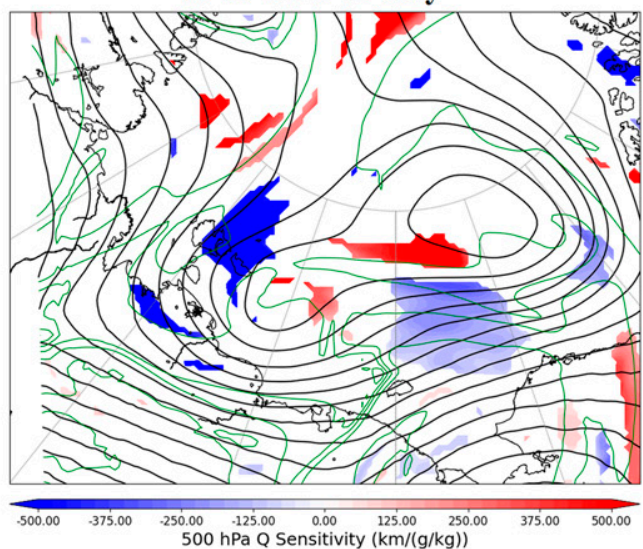

FIG. 10. Ensemble sensitivity of Arctic cyclone (a),(c),(e) amplitude and (b),(d),(f) track error to water vapor mixing ratio at $500 \mathrm{hPa}$ at (a),(b) the initial time; (c),(d) 12-h forecast time; and (e),(f) 24-h forecast time. Only values statistically significant at the $90 \%$ level are plotted. Baseline forecast 500 -hPa geopotential height (black) and water vapor mixing ratio (green) are overlaid and black circles in (a)-(c) highlight region of moisture sensitivity discussed in text.

assimilated observations. It is likely that a difference of $2 \mathrm{hPa}$ is close to the uncertainty of the GFS analysis in representing the true amplitude of the surface cyclone. In general, the data denial impacts the track error more substantially than the amplitude error and is therefore the focus of the more targeted OSEs described below.

Three sondes in particular were selected for targeted OSEs, based on their proximity to the region of cyclogenesis. The 
A) Amplitude

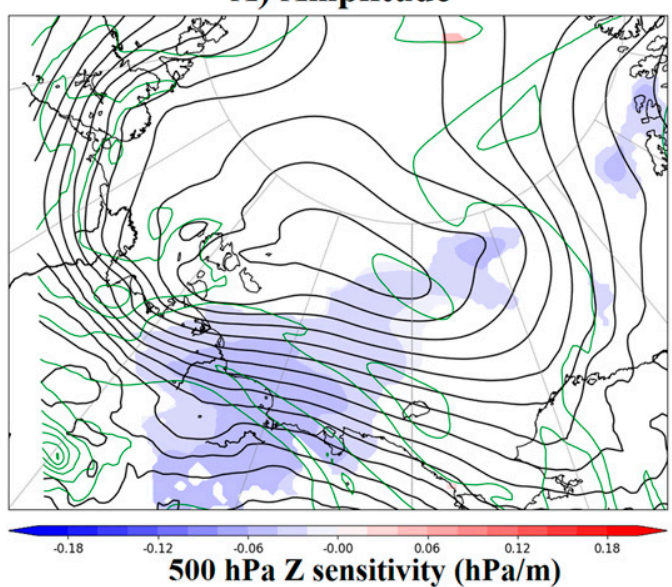

B) Track

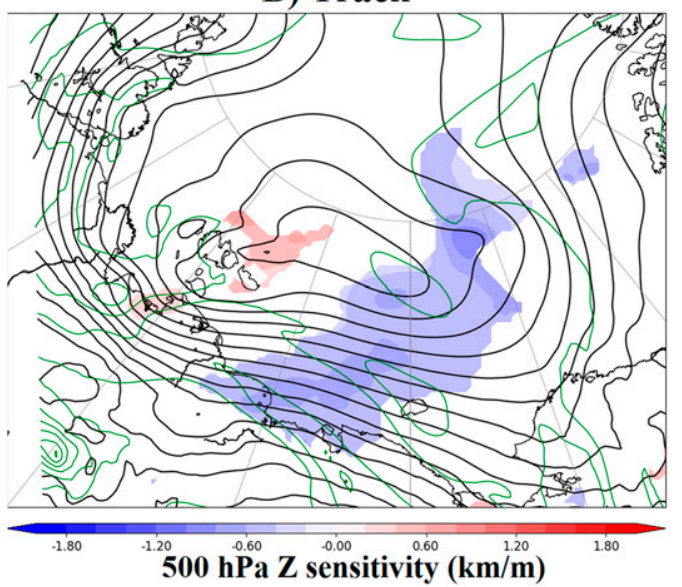

FIG. 11. Ensemble sensitivity of Arctic cyclone (a) amplitude and (b) track error to initial-time 500-hPa geopotential height (shading). Only values statistically significant at the $90 \%$ level are plotted. Initial-time ensemble-mean 500-hPa geopotential height (black contours) and water vapor mixing ratio (green contours) are also shown.

ESA results discussed above also suggest several features corresponding to Arctic cyclone track and amplitude errors that these sondes may be able to help constrain if the model contains substantial errors relative to the observations. Such features potentially include the region around the TPV at tropopause level (Fig. 9), the region immediately downstream of the $500-\mathrm{hPa}$ trough (Fig. 10a), the jet structure at $500 \mathrm{hPa}$ (Fig. 11a), the 500-hPa trough corresponding to the higherlevel TPV (Fig. 11b), and the lower-troposphere temperature in the coastal baroclinic zone (Fig. 12). Although not all of these features were well sampled, so the model error relative to observations is unknown, denying information from only the three sondes in Fig. 5 (red line in Fig. 13) accounts for about half of the increase in track error that resulted from omitting all observations (i.e., noda), although the difference is not quite outside of the two-standard-deviation confidence interval on baseline, even for the track error.

Experiments denying only a single variable from the three sondes were also conducted and shown in Fig. 13 as $o s e 3 \_t$, ose $3 \_q$, and ose $3 \_u v$ for temperature, moisture, and wind variables, respectively. Although denying moisture and wind variables from the three well-placed sondes does lead to slight increases in track error, most of the track error increase in ose 3 is achieved by only denying the temperature observations (orange line in Fig. 13a). In other words, the temperature observations from the few sondes that happened to be placed near the region of cyclogenesis had a greater impact on reducing the surface track error of the Arctic cyclone than other
A) Amplitude

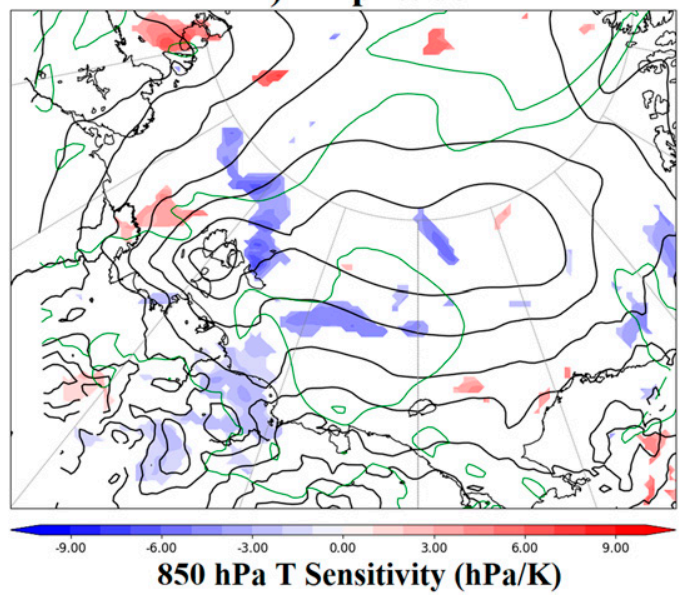

B) Track

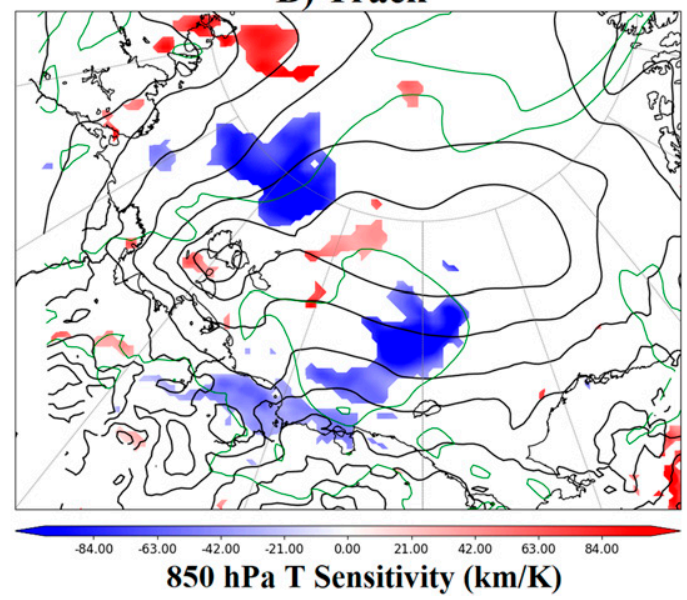

FIG. 12. Ensemble sensitivity of Arctic cyclone (a) amplitude and (b) track error to initial-time 850-hPa temperature (shading). Only values statistically significant at the $90 \%$ level are plotted. Initial-time ensemble-mean 850-hPa geopotential height (black contours) and water vapor mixing ratio (green contours) are also shown. 

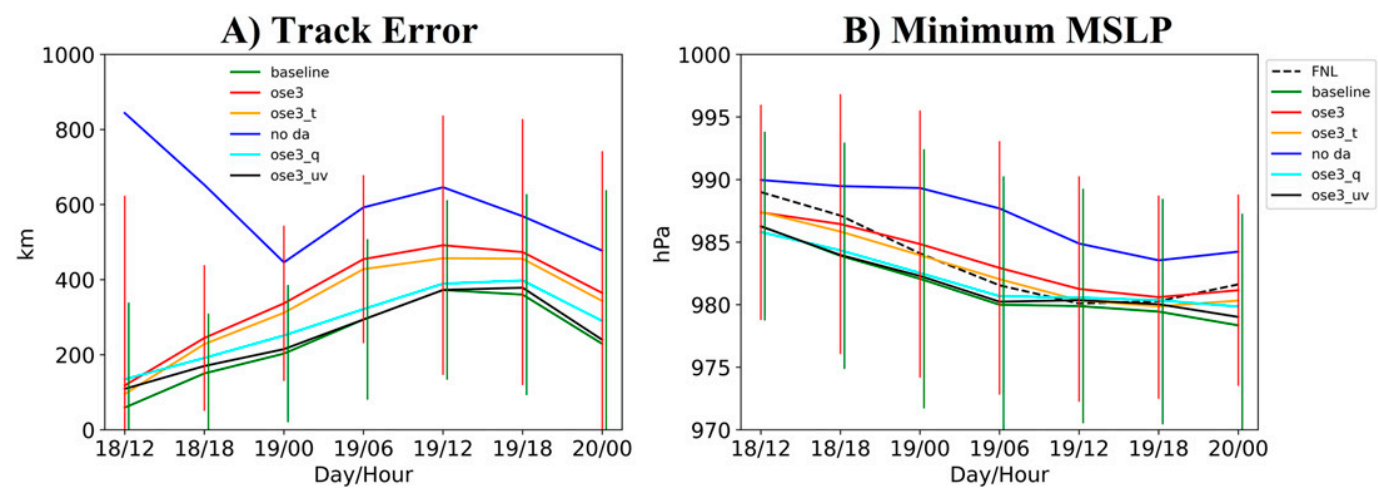

FIG. 13. Forecast (a) Arctic cyclone track error and (b) surface pressure minimum for the noda, baseline, ose3, $o s e 3 \_t, o s e 3 \_q$, and ose $3 \_u v$ experiments. Confidence intervals of the ose 3 and baseline deterministic forecast error show plus and minus two standard deviations of the errors from individual ensemble members.

variables from the same sondes. The relatively small impact of the wind observations in this case is partly a result of some wind observations being flagged as failing quality control checks in the NCEP observation files, and partly a result of the weak flow within the center of the TPV where a sonde that contributed to important (see below) temperature increments was located. The lesser impact of the moisture variable than the temperature variable is consistent with the ESA results, showing coherent and statistically significant large areas of sensitivity to temperature and geopotential height, but in general much smaller-scale features for moisture. The result is that the differences in moisture between the ose $3 \_t$ and baseline forecast do not project strongly onto the sensitive feature identified in the ESA (Fig. 14). In particular the region of large sensitivity follows the downstream ridge axis in the ESA (Fig. 10c; black circle), but this region actually shows less forecast difference between ose3_t and baseline during the forecast than surrounding regions (Fig. 14b; black circle). At upper levels, the lack of moisture impact is also due to the fact that only moisture observations up to $300 \mathrm{hPa}$ are assimilated. Thus, the greater impact of temperature observations than wind and moisture observations is likely a result of the challenges of assimilating moisture at high levels where humidity is low and maintaining the quality of wind observations without rejecting potentially good observations.

Subjective evaluation of the forecast difference with and without the temperature information from the three wellplaced sondes reveals the physical mechanisms through which these observations improved the Arctic cyclone track forecast. The temperature observations helped to constrain the detailed structure of the 500-hPa trough associated with the TPV (i.e., its amplitude), the position of the amplifying Rossby wave as indicated by the large-scale dipole pattern upstream and downstream of the TPV, and the strength of a shortwave ridge in the jet downstream of the TPV (Fig. 15a). In general, the denial of temperature observations weakened the TPV and led to an overall more progressive pattern including both an eastward shift of the large-scale trough and a more zonal jet
A) ose 3 t minus baseline: 00 UTC 17 July

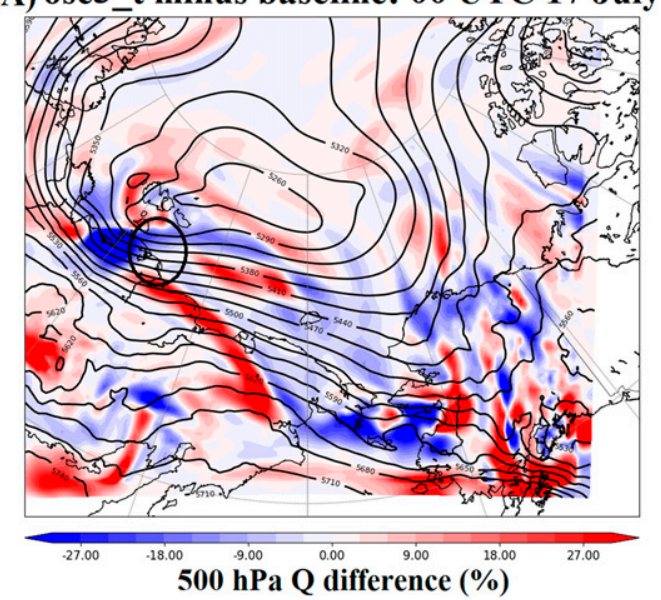

B)ose 3 t minus baseline: 00 UTC 18 July

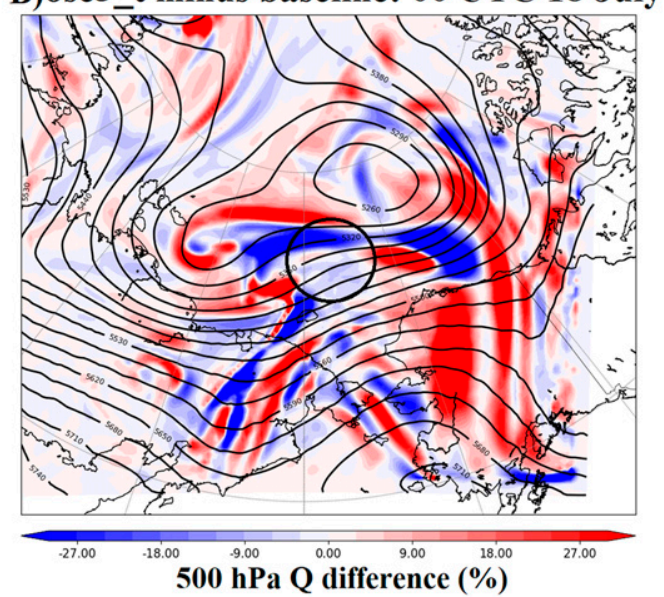

FIG. 14. Percentage difference in 500-hPa water vapor mixing ratio of $o s e 3 \_t$ forecast minus baseline forecast at (a) 0000 UTC $17 \mathrm{Jul}$ and (b) 0000 UTC $18 \mathrm{Jul}$. The 500-hPa geopotential height in baseline forecast is overlaid (black contours) and black circles highlight the regions circled in Fig. 10 and discussed in the text. 
A) ose3t-baseline difference $500 \mathrm{hPa} \mathrm{Z}$ at 0600 UTC 17 July

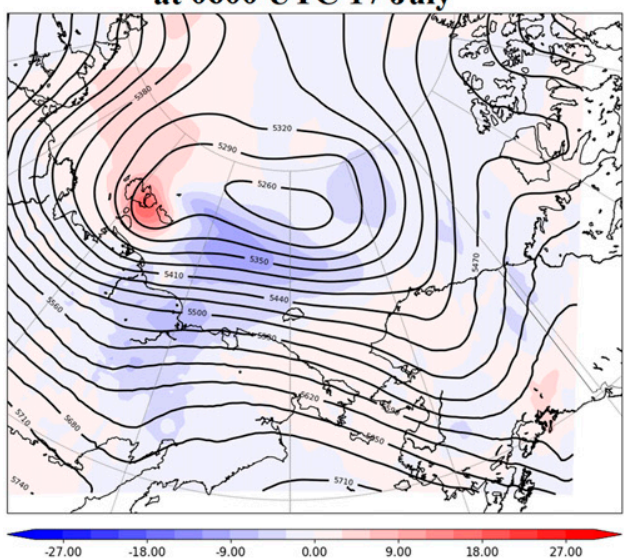

B) ose3t-baseline difference $500 \mathrm{hPa} \mathrm{Z}$ at 0600 UTC 18 July

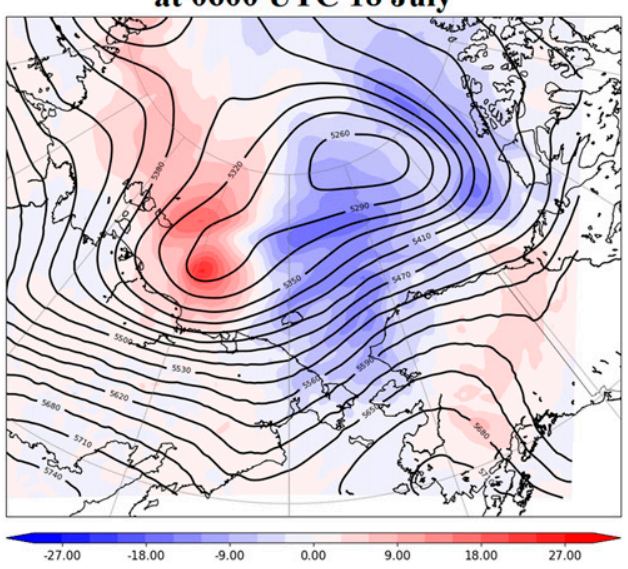

C) ose3t-baseline difference $500 \mathrm{hPa} \mathrm{Z}$ at 0600 UTC 19 July

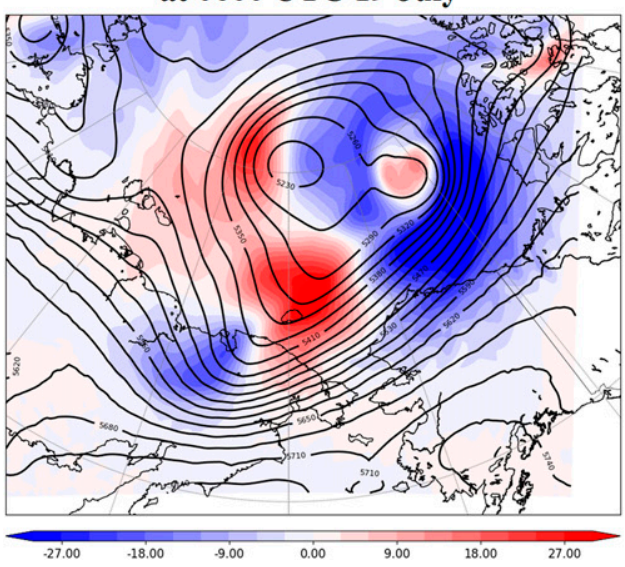

D) Surface and tropopause features at 0600 UTC 17 July

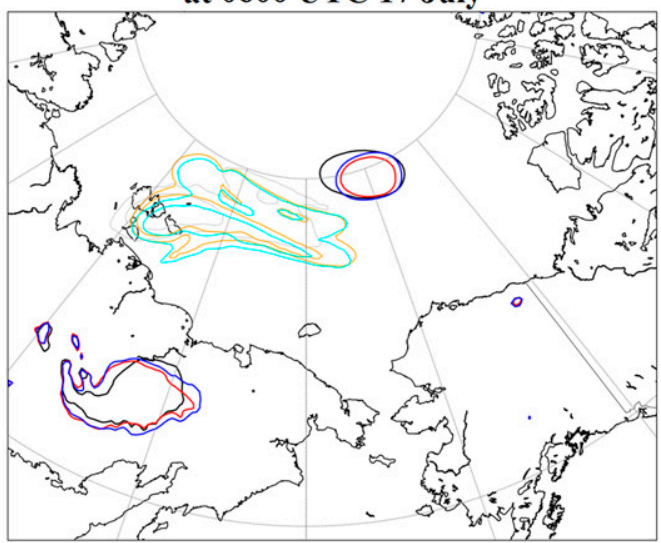

E) Surface and tropopause features at 0600 UTC 18 July

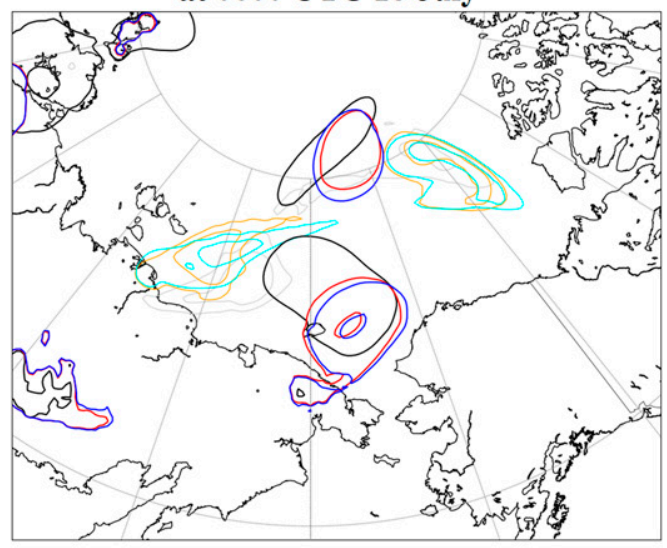

F) Surface and tropopause features at 0600 UTC 19 July

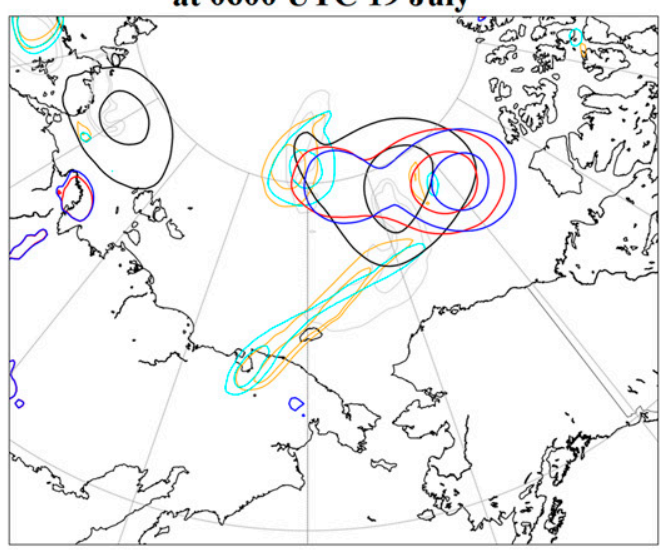

FIG. 15. (left) The baseline forecast 500-hPa geopotential height (black contours) and the difference of the ose $3 \_t$ forecast 500-hPa geopotential height minus the baseline forecast (shading) at (a) 0600 UTC 17 Jul, (b) 0600 UTC 18 Jul, and (c) 0600 UTC 19 Jul. (right) The key surface and tropopause-level features at (d) 0600 UTC 17 Jul, (e) 0600 UTC $18 \mathrm{Jul}$, and (f) 0600 UTC 19 Jul. Black, red, and blue contours in (d)-(f) are surface pressure in GFS analysis, baseline forecast, and ose3_t forecast, respectively, at the 988- and 994-hPa contour levels. Gray, orange, and cyan contours are potential temperature on the 2-PVU surface in GFS analysis, baseline forecast, and ose3_t forecast, respectively, at the 301- and 304-K contour levels. 
downstream of the TPV (Figs. 15a-c). The slightly weaker TPV did not dig as far south into the jet (Fig. 15e; cyan contour), and advected in a more northeasterly than northerly direction as it was elongated by interaction with the jet stream (Fig. 15f; cyan contour). Together with the more eastward location of the large-scale trough, these differences resulted in an eastward displacement of the surface cyclone track in ose 3 t $t$ by 0600 UTC 19 July (Fig. 15f; blue contour) compared to the baseline forecast (Fig. 15f; red contour).

\section{Summary and discussion}

This study aims to better understand the impacts of existing Arctic sonde observations on predictions of the track and intensity of an Arctic cyclone. In particular, the selected Arctic cyclone resulted from a TPV-induced Rossby wave initiation event and was further strengthened and maintained by the TPV. A series of data denial OSEs were conducted and interpreted in the context of an ESA using the ensemble of analyses resulting from assimilating all available observations.

The ESA showed that the large-scale structure of the Rossby wave pattern was potentially important for both the Arctic cyclone track and amplitude forecasts. The moisture analysis in the vicinity of the warm conveyor belt was significantly correlated with cyclone amplitude, although this feature was not well sampled in the existing observations. The 500-hPa geopotential height sensitivity also suggested the importance of the structure of the downstream ridge for both Arctic cyclone track and amplitude errors, and the amplitude of the midtroposphere disturbance associated with the TPV for Arctic cyclone track errors. At lower levels (e.g., $850 \mathrm{hPa}$ ) statistically significant temperature sensitivity was found in the Siberian air mass in which cyclogenesis began for amplitude, and on the cold sides of an Arctic ocean cold front and a Siberian coastal front for track errors.

The data denial experiments revealed that the Arctic cyclone track error was more clearly sensitive to assimilation of the available observations than the Arctic cyclone amplitude error. While lower-level observations initially impacted the track error (as quantified by MSLP, a low-level variable) more than the upper-level observations, it was the upper-level observations that eventually had the dominant impact. It was also shown that denying temperature data from just three well-placed sondes could substantially increase the cyclone track error. This is because the sondes that happened to sample the TPV itself, or the structure of the upper-level jet downstream from the TPV, were able to better constrain the TPV amplitude and the strength of downstream ridging. These aspects of the analysis affected how progressive the Arctic cyclone development was during the forecast period, and thus the forecast track error. Although more cases and systematic study will still be needed, these results suggest optimism that further improvements to the predictability of Arctic cyclone forecasts may be obtainable through even a small number of well-placed observations, in particular upper-level temperature observations.

The ESA suggests that the OSE results may only be giving an incomplete understanding of the important processes to sample with sonde observations to maximize the practical predictability of this Arctic cyclone event. There were several potentially important features identified by the ESA that were not well sampled by the existing sonde observations at the analysis time. In particular, the moisture content and vertical structure within the warm conveyor belts, the upper-level height field over the Arctic Ocean, and the low-level baroclinic zones over the Arctic Ocean and along the Siberian coast were not well sampled by the existing sonde observations. However, there are several caveats regarding the ESA that should be considered.

The ESA can only reveal the linear correlations of these features to the forecast errors, but not necessarily causation and may not reflect nonlinearities in the forecast sensitivity. Furthermore, spatial correlation in the sensitivity fields have been shown to affect ESA results but not results from other methods such as adjoint-based sensitivity (Ancell and Hakim 2007). Ancell and Hakim (2007) found that the ESA tended to emphasize synoptic-scale features while the adjoint sensitivity better highlighted mesoscale features with more complex spatial structure. Thus, there may also be additional mesoscale features that were not revealed in this study, which could also be better sampled by the observation network in order to reduce the Arctic cyclone forecast errors. Additional study focused on targeting specific features to observe with additional Arctic observations, using ESA and adjoint-based sensitivity, and also including additional cases, is recommended for future work. The forecast improvements achievable by expanding the observation network for data assimilation may be ultimately limited by the contribution to forecast errors from the model and physics uncertainty, which is also left for consideration in future study.

Acknowledgments. The work is primarily supported by N00014-18-1-2226. The authors are grateful to David Bromwich, Le Shang Bai, and Keith Hines for providing, and answering questions about, the Polar WRF modifications to WRF, and grateful to the support from James Doyle during the course of the work. This work used the Extreme Science and Engineering Discovery Environment (XSEDE), which is supported by National Science Foundation Grant ACI-1053575. Computing for this project was also performed at the OU Supercomputing Center for Education and Research (OSCER) at the University of Oklahoma (OU). The manuscript was much improved by the suggestions of three anonymous reviewers.

Data availability statement. All WRF forecast data produced during this study have been archived locally and are available upon request to the authors.

\section{REFERENCES}

Aizawa, T., H. L. Tanaka, and M. Satoh, 2014: Rapid development of arctic cyclone in June 2008 simulated by the cloud resolving global model NICAM. Meteor. Atmos. Phys., 126, 105-117, https://doi.org/10.1007/s00703-013-0272-6.

Ancell, B., and G. J. Hakim, 2007: Comparing adjoint- and ensemble-sensitivity analysis with applications to observation targeting. Mon. Wea. Rev., 135, 4117-4134, https://doi.org/ 10.1175/2007MWR1904.1. 
Barlage, M., and Coauthors, 2010: Noah land surface model modifications to improve snowpack prediction in the Colorado Rocky Mountains. J. Geophys. Res., 115, D22101, https:// doi.org/10.1029/2009JD013470.

Bednarczyk, C. N., and B. C. Ancell, 2015: Ensemble sensitivity analysis applied to a southern plains convective event. Mon. Wea. Rev., 143, 230-249, https://doi.org/10.1175/MWR-D13-00321.1.

Boisvert, L. N., A. A. Petty, and J. C. Stroeve, 2016: The impact of the extreme winter 2015/16 Arctic cyclone on the BarentsKara Seas. Mon. Wea. Rev., 144, 4279-4287, https://doi.org/ 10.1175/MWR-D-16-0234.1.

Bradley, A., F. Massonnet, and J. Baeseman, 2015: Climate and Cryosphere Contributions for the Year of Polar Prediction (YOPP). WCRP, 5 pp., Polarmet.osu.edu/YOPP-SH/YOPP_ CliC_2015.pdf.

Bromwich, D. H., K. M. Hines, and L.-S. Bai, 2009: Development and testing of Polar Weather Research and Forecasting model: 2. Arctic Ocean. J. Geophys. Res., 114, D08122, https:// doi.org/10.1029/2008JD010300.

Cavallo, S. M., and G. J. Hakim, 2009: Potential vorticity diagnosis of a tropopause polar cyclone. Mon. Wea. Rev., 137, 13581371, https://doi.org/10.1175/2008MWR2670.1.

$\longrightarrow$, and - 2010: Composite structure of tropopause polar cyclones. Mon. Wea. Rev., 138, 3840-3857, https://doi.org/ 10.1175/2010MWR3371.1.

— Vortex intensity change. J. Atmos. Sci., 70, 3359-3373, https:// doi.org/10.1175/JAS-D-13-088.1.

Chang, E. K. M., M. Zheng, and K. Raeder, 2013: Medium-range ensemble sensitivity analysis of two extreme Pacific extratropical cyclones. Mon. Wea. Rev., 141, 211-231, https:// doi.org/10.1175/MWR-D-11-00304.1.

Clough, S. A., M. W. Shephard, E. J. Mlawer, J. S. Delamere, M. J. Iacono, K. Cady-Pereira, S. Boukabara, and P. D. Brown, 2005: Atmospheric radiative transfer modeling: A summary of the AER codes. J. Quant. Spectrosc. Radiat. Transfer, 91, 233 244, https://doi.org/10.1016/j.jqsrt.2004.05.058.

Day, J. J., I. Sandu, L. Magnusson, M. J. Rodwell, H. Lawrence, N. Bormann, and T. Jung, 2019: Increased Arctic influence on the midlatitude flow during Scandinavian blocking episodes. Quart. J. Roy. Meteor. Soc., 145, 3846-3862, https://doi.org/ 10.1002/qj.3673.

Gaspari, G., and S. E. Cohn, 1999: Construction of correlation functions in two and three dimensions. Quart. J. Roy. Meteor. Soc., 125, 723-757, https://doi.org/10.1002/qj.49712555417.

Hines, K. M., and D. H. Bromwich, 2008: Development and testing of polar Weather Research and Forecasting (WRF) Model. Part I: Greenland ice sheet meteorology. Mon. Wea. Rev., 136, 1971-1989, https://doi.org/10.1175/2007MWR2112.1.

—, and —, 2017: Simulation of late summer Arctic clouds during ASCOS with Polar WRF. Mon. Wea. Rev., 145, 521541, https://doi.org/10.1175/MWR-D-16-0079.1.

,,-- L. Bai, M. Barlage, and A. G. Slater, 2011: Development and testing of polar WRF. Part III: Arctic land. J. Climate, 24, 26-48, https://doi.org/10.1175/2010JCLI3460.1.

,,--- , C. M. Bitz, J. G. Powers, and K. W. Manning, 2015: Sea ice enhancements to Polar WRF. Mon. Wea. Rev., 143, 2363-2385, https://doi.org/10.1175/MWR-D-14-00344.1.

IASC, 2016: MOSAIC: Multidisciplinary drifting Observatory for the Study of Arctic Climate-Science Plan. International Arctic Science Committee (IASC), 78 pp., https://icarp.iasc.info/images/ articles/news/MosaicSciencePlan2016.pdf.
Inoue, J., T. Enomoto, and M. E. Hori, 2013: The impact of radiosonde data over the ice-free Arctic Ocean on the atmospheric circulation in the Northern Hemisphere. Geophys. Res. Lett., 40, 864-869, https://doi.org/10.1002/grl.50207.

Jung, T., M. A. Kasper, T. Semmler, and S. Serrar, 2014: Arctic influence on subseasonal midlatitude prediction. Geophys. Res. Lett., 41, 3676-3680, https://doi.org/10.1002/2014GL059961. , and Coauthors, 2015: Polar lower-latitude linkages and their role in weather and climate prediction. Bull. Amer. Meteor. Soc., 96, ES197-ES200, https://doi.org/10.1175/BAMS-D-1500121.1.

—_, and Coauthors, 2016: Advancing polar prediction capabilities on daily to seasonal time scales. Bull. Amer. Meteor. Soc., 97, 1631-1647, https://doi.org/10.1175/BAMS-D-14-00246.1.

Kerr, C. A., D. J. Stensrud, and X. Wang, 2019: Diagnosing convective dependencies on near-storm environments using ensemble sensitivity analyses. Mon. Wea. Rev., 147, 495-517, https://doi.org/10.1175/MWR-D-18-0140.1.

Kretschmer, M., D. Coumou, J. F. Donges, and J. Runge, 2016: Using causal effect networks to analyze different Arctic drivers of midlatitude winter circulation. J. Climate, 29, 40694081, https://doi.org/10.1175/JCLI-D-15-0654.1.

Morrison, H., J. A. Curry, and V. I. Khvorostyanov, 2005: A new double-moment microphysics parameterization for application in cloud and climate models. Part I: Description. J. Atmos. Sci., 62, 1665-1677, https://doi.org/10.1175/JAS3446.1.

- G. Thompson, and V. Tatarskii, 2009: Impact of cloud microphysics on the development of trailing stratiform precipitation in a simulated squall line: Comparison of one- and twomoment schemes. Mon. Wea. Rev., 137, 991-1007, https:// doi.org/10.1175/2008MWR2556.1.

Noh, Y., W. G. Cheon, S. Y. Hong, and S. Raasch, 2003: Improvement of the K-profile model for the planetary boundary layer based on large eddy simulation data. Bound.-Layer Meteor., 107, 401-427, https://doi.org/10.1023/A:1022146015946.

Röthlisberger, M., O. Martius, and H. Wernli, 2018: Northern Hemisphere Rossby wave initiation events on the extratropical jet-A climatological analysis. J. Climate, 31, 743-760, https://doi.org/10.1175/JCLI-D-17-0346.1.

Sato, K., J. Inoue, A. Yamazaki, J.-H. Kim, A. Makshtas, V. Kustov, M. Maturilli, and K. Dethloff, 2018: Impact on predictability of tropical and mid-latitude cyclones by extra Arctic observations. Sci. Rep., 8, 12104, https://doi.org/10.1038/ s41598-018-30594-4.

Simmonds, I., and I. Rudeva, 2012: The great Arctic cyclone of August 2012. Geophys. Res. Lett., 39, L230709, https://doi.org/ 10.1029/2012GL054259.

Skamarock, W. C., and Coauthors, 2008: A description of the Advanced Research WRF version 3. NCAR Tech. Note NCAR/ TN-475+STR, 113 pp., https://doi.org/10.5065/D68S4MVH.

Smith, L. C., and S. R. Stephenson, 2013: New trans-Arctic shipping routes navigable by midcentury. Proc. Natl. Acad. Sci. USA, 110, E1191-E1195, https://doi.org/10.1073/pnas.1214212110.

Sodemann, H., and A. Stohl, 2013: Moisture origin and meridional transport in atmospheric rivers and their association with multiple cyclones. Mon. Wea. Rev., 141, 2850-2868, https:// doi.org/10.1175/MWR-D-12-00256.1.

Tanaka, H. L., A. Yamagami, and S. Takahashi, 2012: The structure and behavior of the arctic cyclone in summer analyzed by the JRA-25/JCDAS data. Polar Sci., 6, 55-69, https://doi.org/ 10.1016/j.polar.2012.03.001.

Tao, W., J. Zhang, Y. Fu, and X. Zhang, 2017: Driving roles of tropospheric and stratospheric thermal anomalies in intensification 
and persistence of the Arctic superstorm in 2012. Geophys. Res. Lett., 44, 10 017-10 025, https://doi.org/10.1002/ 2017 GL074778.

Taylor, P. C., S. Kato, K.-M. Xu, and M. Cai, 2015: Covariance between Arctic sea ice and clouds within atmospheric state regimes at the satellite footprint level. J. Geophys. Res. Atmos., 120, 12 656-12 678, https://doi.org/10.1002/2015JD023520.

Torn, R. D., and G. J. Hakim, 2008: Ensemble-based sensitivity analysis. Mon. Wea. Rev., 136, 663-677, https://doi.org/10.1175/ 2007MWR2132.1.

Wang, X., and T. Lei, 2014: GSI-based four-dimensional ensemblevariational (4DEnsVar) data assimilation: Formulation and single-resolution experiments with real data for NCEP Global Forecast System. Mon. Wea. Rev., 142, 3303-3325, https:// doi.org/10.1175/MWR-D-13-00303.1.

, D. Parrish, D. Kleist, and J. Whitaker, 2013: GSI 3DVarbased ensemble-variational hybrid data assimilation for NCEP Global Forecast System: Single-resolution experiments. Mon. Wea. Rev., 141, 4098-4117, https://doi.org/10.1175/MWR-D-1200141.1.

Whitaker, J. S., and T. M. Hamill, 2002: Ensemble data assimilation without perturbed observations. Mon. Wea. Rev., 130, 1913-1924, https://doi.org/10.1175/1520-0493(2002)130<1913: EDAWPO $>2.0 . \mathrm{CO} ; 2$.

—, and — 2012: Evaluating methods to account for system errors in ensemble data assimilation. Mon. Wea. Rev., 140, 3078-3089, https://doi.org/10.1175/MWR-D-11-00276.1.
Wilson, A. B., D. H. Bromwich, and K. M. Hines, 2011: Evaluation of polar WRF forecasts on the Arctic system reanalysis domain: Surface and upper air analysis. J. Geophys. Res., 116, D11112, https://doi.org/10.1029/2010JD015013.

- - — and - 2012: Evaluation of polar WRF forecasts on the Arctic system reanalysis domain: 2. Atmospheric hydrologic cycle. J. Geophys. Res., 117, D04107, https://doi.org/ 10.1029/2011JD016765.

Wirth, V., M. Riemer, E. K. M. Chang, and O. Martius, 2018: Rossby wave packets on the midlatitude waveguide-A review. Mon. Wea. Rev., 146, 1965-2001, https://doi.org/10.1175/ MWR-D-16-0483.1.

Yamagami, A., M. Matsueda, and H. L. Tanaka, 2017: Extreme arctic cyclone in August 2016. Atmos. Sci. Lett., 18, 307-314, https://doi.org/10.1002/asl.757.

,-- , and,- 2018 : Medium-range forecast skill for extraordinary Arctic cyclones in summer of 2008-2016. Geophys. Res. Lett., 45, 4429-4437, https://doi.org/10.1029/2018GL077278.

Yamazaki, A., J. Inoue, K. Dethloff, M. Maturilli, and G. König-Langlo, 2015: Impact of radiosonde observations on forecasting summertime Arctic cyclone formation. J. Geophys. Res. Atmos., 120, 3249-3273, https://doi.org/10.1002/ 2014JD022925.

Zhou, X., Y. Zhu, D. Hou, Y. Luo, J. Peng, and R. Wobus, 2017: Performance of the new NCEP Global Ensemble Forecast System in a parallel experiment. Wea. Forecasting, 32, 19892004, https://doi.org/10.1175/WAF-D-17-0023.1. 